\title{
Impact of Anemia in Pregnant Women on the Neonatal Conditions
}

\author{
Raisa Aringazina* (D), Gulnara Kurmanalina ${ }^{1}$, Yerlan Bazargaliyev ${ }^{1}$, Victoria Kononets $^{2}$, Bakhtiyar Kurmanalin ${ }^{3}$, Anes Bekkuzhin $^{4}$ \\ ${ }^{1}$ Department of Internal Diseases, West Kazakhstan Marat Ospanov Medical University, Aktobe, Kazakhstan; ${ }^{2}$ Department \\ of Natural Sciences, West Kazakhstan Marat Ospanov Medical University, Aktobe, Kazakhstan; ${ }^{3}$ Department of Children's \\ Diseases, West Kazakhstan Marat Ospanov Medical University, Aktobe, Kazakhstan; ${ }^{4}$ Department of Chemical Disciplines, \\ West Kazakhstan Marat Ospanov Medical University, Aktobe, Kazakhstan
}

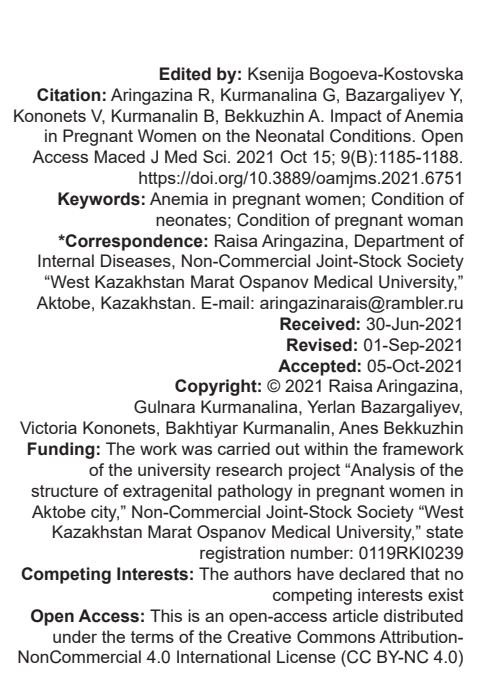

Abstract

BACKGROUND: True iron deficiency anemia in pregnant women has been a pressing obstetric issue for many years and is one of the most common complications of pregnancy in the world, particularly in developing countries.

AIM: The aim of the study was to study the condition of neonates born to women with iron deficiency anemia.

METHODS: The retrospective analysis method was used to assess 230 patient medical files in the maternity and pregnancy pathology departments. The patients were divided into 2 groups: 1 - patients suffering from iron deficiency anemia $(n=113), 2$ - patients without iron deficiency anemia $(n=117)$. The diagnosis of true iron deficiency anemia in pregnant women was established according to the WHO classification based on the hemogram and indices of transport iron content, total serum iron-binding capacity, and the concentration of ferritin in the blood. The condition of a child was assessed on the basis of the APGAR scale, height and weight at birth, and the presence of diagnosed pathology at birth.

RESULTS: The mass-growth index in the group of neonates born to mothers with anemia statistically was significantly lower compared to the control group. The proportion of neonates with hypotrophy in the group born to mothers with anemia statistically was significantly higher. Body length and birth condition indices assessed according to the APGAR scale were virtually identical across the groups.

CONCLUSIONS: Anemia during pregnancy affects the trophism of a fetus, which is largely reflected in the health of neonates. Treating maternal anemia is important to prevent or decrease the incidence of underweight in infants at birth.

\section{Introduction}

Anemia in pregnant women has been a pressing obstetric issue for many years and is one of the most common complications of pregnancy in the world [1], [2], [3]. Notwithstanding the best efforts of national health programs to provide optimal prenatal care for all pregnant women and recommend screening for anemia at their first prenatal visit, more than half of pregnant women worldwide suffer from this problem [4].

Iron deficiency anemia in women is common in all age groups because of the peculiarities of their body physiology, hormonal homeostasis, and the realization of reproductive function. One in three women of reproductive age and one in two pregnant women experience a pronounced iron deficiency [5]. Expectant mothers are traditionally regarded as the most vulnerable group. Statistics indicate that there are at least 50 million pregnant women worldwide affected by this disease [6].

During pregnancy, a woman's body increases the amount of fluid and the volume of circulating blood.
Due to this, the share of hemoglobin in the total blood volume decreases. This is a normal phenomenon, which is why the lower limit for the amount of hemoglobin during pregnancy is set at $110 \mathrm{~g} / \mathrm{l}$ (while the norm for a non-pregnant woman is 120-140 g/l). However, a further drop in hemoglobin levels is dangerous for the health and even life of an expectant mother.

The most common anemia during pregnancy is iron deficiency anemia (about 75\%), sometimes combined with megaloblastic anemia with folic acid deficiency [7].

Iron deficiency anemia in pregnant women raises the risk of complications during labor, studies by Indian scientists indicate that anemia accounts for $20-40 \%$ of maternal deaths [8].

However, anemia endangers not just women, but also children; lack of appropriate and timely treatment may lead to the development of iron deficiency in the fetus and newborn [9]; the risk of low birth weight is tripled; premature births are doubled, and the incidence of stillbirths has increased by 1.4 [10], [11].

Certainly, maternal hemic hypoxia plays an important role. However, it can only directly affect fetal 
oxygenation when maternal hemoglobin levels drop to $85 \mathrm{~g} / \mathrm{l}$ and anaerobic oxidation mechanisms are activated [6].

It is, therefore, important to study fetal status in anemic pregnant women. The aim of this study was to examine the condition of neonates born to women with anemia during pregnancy.

\section{Materials and Methods}

The retrospective analysis method was used to assess 230 patient medical files in the maternity and pregnancy pathology departments. The patients were divided into two groups: 1- patients suffering from iron deficiency anemia $(n=113)$ and 2- patients without iron deficiency anemia $(n=117)$.

The diagnosis of anemia in pregnant women was established according to the WHO classification based on the hemogram and indices of transport iron content, total serum iron-binding capacity, and the concentration of ferritin in the blood. Hemoglobin levels in the blood of pregnant women with mild anemia ranged from 90 to $106 \mathrm{~g} / \mathrm{l}$, with erythrocyte levels ranging from 3.7 to $3.3 \times 10^{12} /$. The blood hemoglobin levels in women with moderate anemia ranged from 89 to $80 \mathrm{~g} / \mathrm{l}$, and erythrocyte levels from 3.2 to $3.0 \times 10^{12} /$. The diagnosis of true anemia was confirmed by the detection of poikilocytes and anisocytes in a blood smear.

Indicators of maternal and child health were assessed and interpreted. The condition of a child was assessed on the basis of the APGAR scale, height and weight at birth, and the presence of diagnosed pathology at birth.

Statistical processing of the survey results was carried out using the statistical software STATISTICA 10. The normality of distribution was verified according to the Shapiro-Wilk and Kolmogorov-Smirnov criteria. In the absence of normal sample distribution, the significance of the differences was determined with a non-parametric Mann-Whitney $U$ test for independent samples. For the qualitative characteristics of the sample, the Pearson's Chi-square test was used. The Spearman's rank correlation coefficient was calculated to determine the relationship between the different parameters.

The research was conducted ethically in accordance with the World Medical Association Declaration of Helsinki. The study was approved by the Local Bioethics Committee at West Kazakhstan Marat Ospanov Medical University, protocol No. 22 as of April 9, 2019.

\section{Results}

The gender distribution of newborns showed that there were 52 boys (44.4\%) and 65 girls (55.6\%) in the comparison group. Among the neonates of anemic mothers, there were 49 boys (43.40\%) and 64 girls (56.6\%).

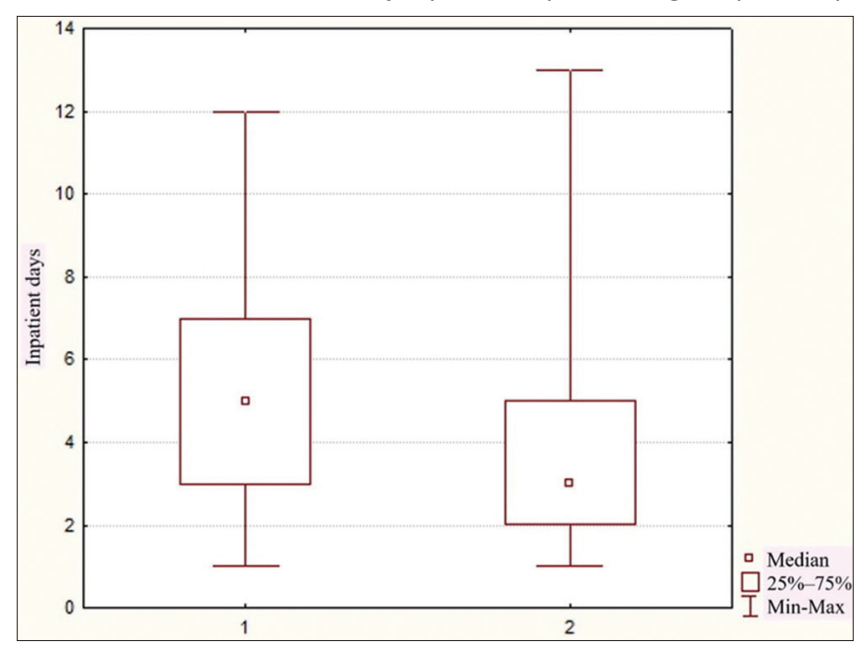

Figure 1: Flow chart of inpatient days distribution

When comparing duration of hospital stay, inpatient days in Group 1 were statistically significantly longer than in Group 2 (Figure 1 and Table 1). In evaluating the correlation relationship, there was a slight effect of several factors on the length of stay in hospital: A woman's age $(r=0.13$; $p<0.05)$, gestational age $(r=-0.24 ; p<$ $0.05)$, and heart rate $(r=0.34 ; p<0.05)$ of pregnant women.

Table 1: Indicators of pregnancy condition upon admission to hospital

\begin{tabular}{llll}
\hline Indicator & $\begin{array}{l}\text { Group 1 }(\mathrm{n}=113) \\
\text { mean (min.-max.) }\end{array}$ & $\begin{array}{l}\text { Group 2 }(\mathrm{n}=117) \\
\text { mean (min.-max.) }\end{array}$ & $\mathrm{p}$ \\
\hline Age, years & $28(24-35)$ & $28(25-33)$ & 0.8001 \\
Height, cm & $162(158-166)$ & $163(158-165)$ & 0.8432 \\
Weight, kg & $71.5(63-79)$ & $70.3(63-80)$ & 0.8171 \\
Gestational age, weeks & $39(38-40)$ & $39(38-40)$ & 0.0430 \\
Inpatient days & $5.3(3-7)$ & $3.1(2-5)$ & 0.0012 \\
BP (systole) mmHg & $120(110-130)$ & $119(110-130)$ & 0.4747 \\
Blood pressure (diastole) mmHg & $77(70-90)$ & $79(70-90)$ & 0.4123 \\
Pulse per minute & $78(72-80)$ & $67(62-75)$ & 0.0118 \\
\hline
\end{tabular}

In addition, a difference can be observed in the pulse of the radial artery. The increased heart rate in patients with anemia seems to be associated with a compensatory protection mechanism against hypoxia.

The weight was lower in children born to mothers who had pregnancy accompanied by anemia (Flow chart 2). Body length and birth status on the APGAR scale were not significantly different for each group (Table 2).

The mean value of the mass-growth index of neonates from mothers with true iron deficiency anemia

Table 2: Indicators of neonatal condition at birth

\begin{tabular}{|c|c|c|c|}
\hline Indicator & $\begin{array}{l}\text { Group } 1(n=113) \\
\text { mean (min.-max.) }\end{array}$ & $\begin{array}{l}\text { Group } 2(n=117) \\
\text { mean }(\text { min.-max.) }\end{array}$ & $\mathrm{p}$ \\
\hline Height, cm & $53.2(51-55)$ & $54.1(52-55)$ & 0.2101 \\
\hline Weight, kg & $3.440(3.170-3.680)$ & $3.612(3.330-3.836)$ & 0.0256 \\
\hline $\begin{array}{l}\text { Mass-growth index (Quatelet 1), } \\
\mathrm{g} / \mathrm{cm}\end{array}$ & $63.4(56.1-66.8)$ & $66.4(58.4-70.1)$ & 0.0236 \\
\hline APGAR, scores & $9.3(9-10)$ & $9.5(9-10)$ & 0.6469 \\
\hline
\end{tabular}


was $63.4 \pm 9.7$. The proportion of children exhibiting hypotrophic signs was $24.8 \%(\mathrm{n}=28$; $\mathrm{Cl} 16.8-32.7)$. The mean value of the mass growth index for the control group neonates is $66.4 \pm 5.8$. The proportion of newborn exhibiting hypotrophic signs was $12.0 \%$ ( $n=14 ; \mathrm{Cl} 6.1-17.8)$. Thus, mass-growth index in the group of neonates born to mothers with iron deficiency anemia was statistically significantly lower than in the control group. It should also be noted that the proportion of neonates suffering from hypotrophy in the group of neonates born to mothers suffering from anemia statistically was significantly higher $(p<0.005)$.

Table 3: Neonatal pathology detected at birth

\begin{tabular}{|c|c|c|c|c|c|}
\hline \multirow[t]{2}{*}{ Pathological conditions } & \multicolumn{2}{|c|}{ Group 1} & \multicolumn{2}{|c|}{ Group 2} & \multirow[t]{2}{*}{$\mathrm{p}$} \\
\hline & $\mathrm{n}$ & $\%$ & $\mathrm{n}$ & $\%$ & \\
\hline Fetal impairment & 5 & 4.4 & 3 & 2.5 & 0.441 \\
\hline Antenatal fetal death & 4 & 3.5 & 1 & 0.8 & 0.162 \\
\hline Congenital heart defect & 3 & 2.6 & 3 & 2.5 & 0.965 \\
\hline Cryptorchidism & 1 & 0.8 & 0 & & 0.307 \\
\hline Single umbilical artery & 1 & 0.8 & 1 & 0.8 & 0.980 \\
\hline Shoulder dystocia & 0 & 0 & 1 & 0.8 & 0.324 \\
\hline Threatening fetal condition & 2 & 1.7 & 0 & & 0.148 \\
\hline Delayed intrauterine development of the fetus & 1 & 0.8 & 0 & & 0.307 \\
\hline
\end{tabular}

Pathological and critical disorders detected in neonates were often diagnosed in the group of children born to mothers with anemia. These included heart defects, intra-uterine fetal retardation, and prenatal death of the fetus. However, the survey findings were not statistically significant (Table 3 and Figure 2).

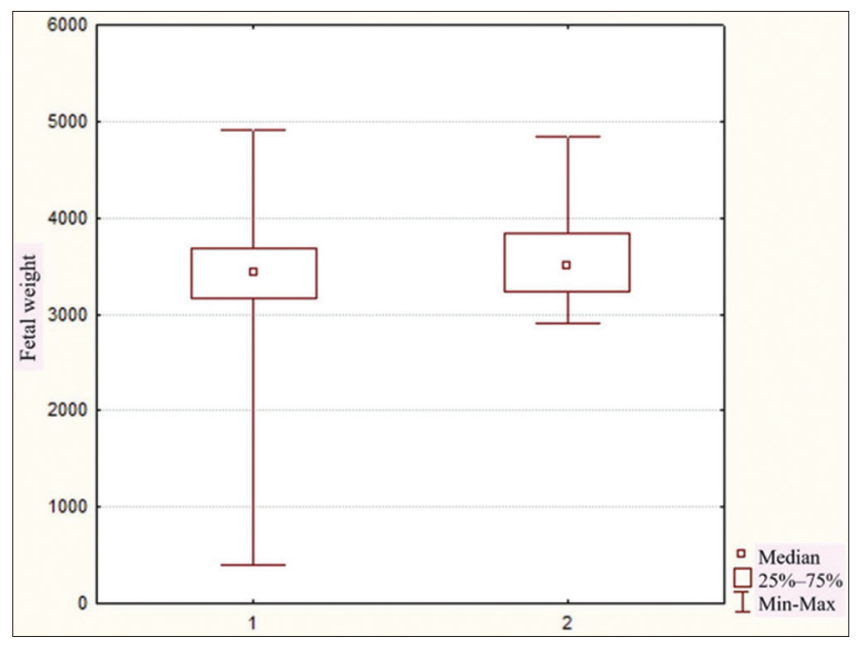

Figure 2: Chart of the fetal birth weight range

\section{Discussion}

This study revealed a statistically significant relationship between maternal true iron deficiency anemia and low birth weight. At the same time, body length and rapid APGAR scores of a newborn were independent of maternal anemia. The weight of a newborn indirectly reflects its maturity and prematurity.

Mass-growth index (Quetelet I) reflects the nutritional status of the intrauterine phase. It was calculated as the ratio between body weight ( $g$ ) and body length $(\mathrm{cm})$. Under normotrophy, the value of the index is 60-70. In the present study, the mean values of the mass-growth index in both groups were within normal limits, but in the group of infants born to mothers with iron deficiency anemia, the mass-growth index values were statistically lower, which was associated with the lower birth weight in this group. In this group, there were also significantly more cases where the mass-growth index values were below the normal values (hypotrophy). Thus, the data obtained may indicate the effect of maternal iron deficiency anemia on the nutritional status of the fetus. Anemia in a pregnant woman can lead to oxygen starvation of the fetus, which leads to a delay in its intrauterine development, resulting in the birth of a baby with low birth weight [12].

Many studies report the impact of anemia on birth weight and an increased risk of premature birth [12], [13], [14], [15]. For example, the study on the relation of maternal anemia with adverse pregnancy and labor outcomes suggests that infants born to anemic women had twice the risk of low birth weight and a higher risk of preterm birth [13]. Another study showed that the frequency of low birth weight babies was significantly higher in mothers with anemia in the third trimester. Preterm births were more frequent in mothers with anemia in the second and third trimesters [15]. A systematic review and metaanalysis of the literature on the association of maternal anemia during pregnancy (especially in the first trimester) with low birth weight in newborns showed a direct correlation [16]. Consequently, maternal anemia must be treated in a timely manner to prevent this anomaly at birth. Another study found a high prevalence of anemia and iron deficiency in early pregnancy and its association with an increased risk of unfavorable pregnancy and neonatal outcomes [17]. Distinct studies suggest that low levels of iron during pregnancy, especially in the third trimester, may be associated with adverse neurological development in offspring [18].

It is important to note that non-pregnant women require $1.5 \mathrm{mg}$ of iron per day. However, during pregnancy, this amount steadily increases in the first trimester by $1 \mathrm{mg} /$ day, in the second trimester by $2 \mathrm{mg} /$ day, and in the third trimester by $3-5 \mathrm{mg} /$ day [19]. Iron requirements during pregnancy may exceed $1000 \mathrm{mg}$, including 500 for erythrocytic multiplication, 300-350 for developing fetus and placenta with various losses during labor [20]. Iron loss is most pronounced at 16-20 weeks of gestation, which coincides with the beginning of the hematopoiesis process in the fetus and the increase in blood weight in pregnant women [21]. Approximately $800-950 \mathrm{mg}$ of iron is spent from a mother's depot during pregnancy and after delivery. The body is capable of restoring iron reserves in 4-5 years. If a woman anticipates an earlier pregnancy, she will inevitably develop anemia [22]. A comprehensive approach to preventing anemia in women of reproductive age is therefore required to improve the hematological status, as also health indicators of mother and child [17], [23]. 


\section{Conclusions}

Thus, anemia in pregnancy affects fetal trophism, which is largely reflected in the health of neonates. Maternal anemia may be considered a risk factor in pregnancy outcomes. Given the relationship between maternal anemia and low birth weight, treatment of maternal anemia is important to prevent or reduce the incidence of low birth weight infants.

\section{References}

1. Mekonnen FA, Ambaw YA, Neri GT. Socio-economic determinants of anemia in pregnancy in North Shoa Zone, Ethiopia. PLoS One. 2018;13(8):e0202734. https://doi. org/10.1371/journal.pone.0202734 PMid:30133527

2. Tulu BD, Atomssa EM, Mengist HM. Determinants of anemia among pregnant women attending antenatal care in Horo Guduru Wollega Zone, West Ethiopia: Unmatched casecontrol study. PLoS One. 2019;14(10):e0224514. https://doi. org/10.1371/journal.pone.0224514

PMid:31671128

3. Fallatah AM, Bifari AE, Alshehri HZ, Wali SM, Alghamdi SA, Almusallam SA, et al. Anemia and cost-effectiveness of complete blood count testing among pregnant women at King Abdulaziz University Hospital: A single tertiary center experience. Cureus. 2020;12(9):e10493. https://doi.org/10.7759/cureus.10493 PMid:33083192

4. Mehra R, Rani J. Anaemia in pregnancy. In: Sharma A, editor. Labor Room Emergencies. Singapore: Springer; 2020. p. 85-94. https://doi.org/10.1007/978-981-10-4953-8_9

5. Tikhomirov Al, Sarsania SI. Problem of iron deficiency anemia in women: Ways of solution. RMJ Mother Child. 2020;3:44-50.

6. Zefirova TP, Yupatov EY, Zamaleeva RS, Mukhametova RR, Khaertdinova LA. Anemia and hemoconcentration in pregnant women. Scope of the problem. Vyatka Med Bull. 2020;1:96-100.

7. Ali SA, Abbasi Z, Feroz A, Hambidge KM, Krebs NF, Westcott JE, et al. Factors associated with anemia among women of the reproductive age group in Thatta district: Study protocol. Reprod Health. 2019;16(1):34. https://doi.org/10.1186/ s12978-019-0688-7

PMid:30885226

8. Grover K, Kumar T, Doda A, Bhutani R, Yadav S, Kaushal P, et al. Prevalence of anaemia and its association with dietary habits among pregnant women in the urban area of Haryana. J Family Med Prim Care. 2020;9(2):783-7. https://doi.org/10.4103/jfmpc. jfmpc_1062_19

PMid:32318420

9. Volkov VG, Akhilgova ZS. Risk factors for early pregnancy losses. Bul New Med Tech. 2020;14:66-72.

10. Haider BA, Olofin I, Wang M, Spiegelman D, Ezzati M, Fawzi WW. Anaemia, prenatal iron use, and risk of adverse pregnancy outcomes: Systematic review and meta-analysis. BMJ. 2013;346:f3443. https://doi.org/10.1136/bmj.f3443 PMid:23794316

11. Sukrat B, Wilasrusmee C, Siribumrungwong B, McEvoy M, Okascharoen C, Attia J, et al. Hemoglobin concentration and pregnancy outcomes: A systematic review and meta-analysis. Biomed Res Int. 2013;2013:769057. https://doi. org/10.1155/2013/769057

\section{PMid:23984406}

12. Rahman MM, Abe SK, Rahman MS, Kanda M, Narita S Bilano $\mathrm{V}$, et al. Maternal anemia and risk of adverse birth and health outcomes in low-and middle-income countries: Systematic review and meta-analysis. Am J Clin Nutr. 2016;103(2):495-504. https://doi.org/10.3945/ajcn.115.107896 PMid:26739036

13. AhankariAS, Myles PR, Dixit JV, Tata LJ, Fogarty AW. Risk factors for maternal anaemia and low birth weight in pregnant women living in rural India: A prospective cohort study. Public Health. 2017;151:63-73. https://doi.org/10.1016/j.puhe.2017.06.023 PMid:28743049

14. Alemu B, Gashu D. Association of maternal anthropometry, hemoglobin and serum zinc concentration during pregnancy with birth weight. Early Hum Dev. 2020;142:104949. https://doi. org/10.1016/j.earlhumdev.2019.104949

PMid:31923646

15. Kumar KJ, Asha N, Murthy DS, Sujatha M, Manjunath V. Maternal anemia in various trimesters and its effect on newborn weight and maturity: An observational study. Int $\mathrm{J}$ Prev Med. 2013;4(2):193-9.

PMid:23543625

16. Rahmati S, Delpishe A, Azami M, Ahmadi MR, Sayehmiri K Maternal anemia during pregnancy and infant low birth weight: A systematic review and meta-analysis. Int J Reprod Biomed. 2017;15(3):125-34.

PMid:28580444

17. Finkelstein JL, Kurpad AV, Bose B, Thomas T, Srinivasan $\mathrm{K}$, Duggan C. Anaemia and iron deficiency in pregnancy and adverse perinatal outcomes in Southern India. Eur J Clin Nutr. 2020;74(1):112-5. https://doi.org/10.1038/s41430-019-0464-3 PMid:31296936

18. Janbek J, Sarki M, Specht IO, Heitmann BL. A systematic literature review of the relation between iron status/anemia in pregnancy and offspring neurodevelopment. Eur J Clin Nutr. 2019;73(12):1561-78. https://doi.org/10.1038/ s41430-019-0400-6 PMid:30783211

19. Johnson S, Lang A, Sturm M, O'Brien SH. Iron deficiency without anemia: A common yet under-recognized diagnosis in young women with heavy menstrual bleeding. J Pediatr Adolesc Gynecol. 2016;29(6):628-31. https://doi.org/10.1182/blood. v124.21.3510.3510 PMid:27262832

20. Scholl TO. Maternal iron status: Relation to fetal growth, length of gestation, and iron endowment of the neonate. Nutr Rev. 2011;69 Suppl 1:S23-9. https://doi. org/10.1111/j.1753-4887.2011.00429.x PMid:22043878

21. Sun D, McLeod A, Gandhi S, Malinowski AK, Shehata N Anemia in pregnancy: A pragmatic approach. Obstet Gynecol Surv. 2017;72(12):730-7. https://doi.org/10.1097/ ogx.0000000000000510 PMid:29280474

22. Williams PA, PoehIman J, Moran K, Siddiqui M, Kataria I, Rego AM, et al. Strategies to address anaemia among pregnant and lactating women in India: A formative research study. Public Health Nutr. 2020;23(5):795-805. https://doi.org/10.1017/s1368980019003938 PMid:32090721

23. Juul SE, Derman RJ, Auerbach M. Perinatal iron deficiency: Implications for mothers and infants. Neonatology. 2019;115(3):269-74. https://doi.org/10.1159/000495978 PMid:30759449 